\title{
Training in the fasted state facilitates re-activation of eEF2 activity during recovery from endurance exercise
}

\author{
K. Van Proeyen $\cdot$ K. De Bock $\cdot$ P. Hespel
}

Accepted: 18 November 2010

(C) Springer-Verlag 2010

\begin{abstract}
Nutrition is an important co-factor in exerciseinduced training adaptations in muscle. We compared the effect of 6 weeks endurance training (3 days/week, 1-2 h at $\left.75 \% \mathrm{VO}_{2 \text { peak }}\right)$ in either the fasted state $(\mathrm{F} ; n=10)$ or in the high carbohydrate state $(\mathrm{CHO}, n=10)$, on $\mathrm{Ca}^{2+}$. dependent intramyocellular signalling in young male volunteers. Subjects in $\mathrm{CHO}$ received a carbohydrate-rich breakfast before each training session, as well as ingested carbohydrates during exercise. Before (pretest) and after (posttest) the training period, subjects performed a $2 \mathrm{~h}$ constant-load exercise bout ( $\sim 70 \%$ of pretest $\mathrm{VO}_{2 \text { peak }}$ ) while ingesting carbohydrates $\left(1 \mathrm{~g} / \mathrm{kg} \mathrm{h}^{-1}\right)$. A muscle biopsy was taken from $\mathrm{m}$. vastus lateralis immediately before and after the test, and after $4 \mathrm{~h}$ of recovery. Compared with pretest, in the posttest basal eukaryotic elongation factor 2 (eEF2) phosphorylation was elevated in CHO $(P<0.05)$, but not in $\mathrm{F}$. In the pretest, exercise increased the degree of eEF2 phosphorylation about twofold $(P<0.05)$, and values returned to baseline within the $4 \mathrm{~h}$ recovery period in each group. However, in the posttest dephosphorylation of eEF2 was negated after recovery in $\mathrm{CHO}$, but not in F. Independent of the dietary condition training enhanced the basal phosphorylation status of Phospholamban at $\mathrm{Thr}^{17}, 5^{\prime}$-AMP-activated protein kinase $\alpha(\mathrm{AMPK} \alpha)$, and Acetyl CoA carboxylase $\beta$ (ACC $\beta)$, and abolished the exercise-induced increase of AMPK $\alpha$ and ACC $\beta(P<0.05)$. In conclusion, training in the fasted
\end{abstract}

Communicated by Martin Flueck.

K. Van Proeyen · K. De Bock $\cdot$ P. Hespel $(\varangle)$

Department of Biomedical Kinesiology,

Research Centre for Exercise and Health, FaBeR-K.U. Leuven,

Tervuursevest 101, 3001 Leuven, Heverlee, Belgium

e-mail: peter.hespel@faber.kuleuven.be state, compared with identical training with ample carbohydrate intake, facilitates post-exercise dephosphorylation of eEF2. This may contribute to rapid re-activation of muscle protein translation following endurance exercise.

Keywords Nutritional status - Metabolic adaptations . AMP-activated protein kinase $\cdot \mathrm{Ca}^{2+}$-calmodulindependent protein kinase $\cdot$ Eukarotic elongation factor 2

\section{Introduction}

It has been well documented that endurance exercise training promotes metabolic adaptations in skeletal muscle resulting in improved endurance performance. The rise in cytosolic $\mathrm{Ca}^{2+}$ concentration during muscle excitation and contraction probably is an important mechanism to alter muscle gene expression and mitochondrial biogenesis in response to training (Chin 2005; Wright 2007). In addition, it has been well established that $5^{\prime}$-AMP-activated protein kinase (AMPK), an ubiquitously expressed serine/thionine multisubstrate protein kinase, plays a pivotal role as a metabolic regulator in skeletal muscle cells (Jorgensen et al. 2006).

During contractions, intramyocellular $\mathrm{Ca}^{2+}$ level increases and initiates a signalling cascade in which calmodulin $(\mathrm{CaM}), \mathrm{a} \mathrm{Ca}^{2+}$ receptor protein, activates $\mathrm{Ca}^{2+}$ calmodulin-dependent protein kinases (CaMK), such as eukaryotic elongation factor 2 (eEF2) kinase, CaMK I, II, and IV, and CaMK kinases (CaMKK) (Hook and Means 2001). It has been demonstrated that CaMKII is a pivotal CaMK in human skeletal muscle, and that phosphorylation of the CaMKII substrate Phospholamban at $\mathrm{Thr}^{17}\left(\mathrm{PLN}^{17}\right)$ reflects in vivo CaMKII activity (Rose et al. 2006). Furthermore, next to LKB1, CaMKK is currently believed to 
act as an upstream kinase of AMPK (Jensen et al. 2007; Hurley et al. 2005; Hawley et al. 2005), which indicates a link between AMPK and $\mathrm{Ca}^{2+}$-signalling. There are data to indicate that AMPK is implicated in the modulation of the protein elongation process by eEF2, at least in muscle cells at rest (Hong-Brown et al. 2007; Horman et al. 2002). On the other hand, Rose et al. (2009) recently showed that inhibition of protein synthesis during exercise in humans by phosphorylation of eEF2, due to the action of $\mathrm{Ca}^{2+}-\mathrm{CaM}-\mathrm{eEF} 2$ kinase, occurred independent of AMPK. Interestingly, recent findings also indicate that increased cytosolic $\mathrm{Ca}^{2+}$ in muscle cells also stimulates the activation of p38 mitogen-activated protein kinase (MAPK) by CaMKII. This in turn enhances peroxisome proliferatoractivated receptor gamma coactivator $1 \alpha$ (PGC-1 $\alpha)$ expression and thereby mitochondrial biogenesis (Wright et al. 2007; Akimoto et al. 2005). Taken together, the above findings indicate that $\mathrm{Ca}^{2+}$-signalling pathways are implicated in metabolic adaptations of skeletal muscles to endurance training.

Evidence is also accumulating to indicate that nutrition is an important co-factor in endurance training-induced muscle remodelling (De Bock et al. 2008; Hansen et al. 2005; Yeo et al. 2008b; Hulston et al. 2010; Nybo et al. 2009). For instance, we have recently found that training in the fasted state during an episode of hypercaloric fat-rich diet in healthy young volunteers, compared with a similar training programme in the high carbohydrate state, increased the expression of muscle GLUT4, AMPK $\alpha$, FAT/ CD36, and CPT1, either at the protein or at the mRNA level (Van Proeyen et al. 2010). Similarly, both FAT/CD36 and membrane-bound fatty acid binding protein $\left(\mathrm{FABP}_{\mathrm{pm}}\right)$ contents were elevated after short-term training in the fasted state, but this effect was negated by carbohydrate intake before and during the training sessions (De Bock et al. 2008). Furthermore, it also has been demonstrated that net muscle protein degradation is increased during prolonged exercise in a carbohydrate-deficient state (Wagenmakers et al. 1991; Jackman et al. 1997), which might in turn stimulate adaptation of signalling pathways implicated in post-exercise protein repair. Support for such assumption contention comes from our recent observation that $\mathrm{p} 70^{\mathrm{s} 6 \mathrm{k}}$ phosphorylation is elevated during recovery from a resistance exercise bout in the fasted state, indicating higher degree of activation of muscle anabolism than after an identical exercise bout in the fed state (Deldique et al. 2010).

It is well known that exercise changes the degree of activation of a wide range of signalling proteins in metabolic pathways involved in skeletal muscle adaptation. For example, consistent exercise training upregulates $\mathrm{AMPK} \alpha$ phosphorylation status in human muscle (Frosig et al. 2004; Lee-Young et al. 2009; Benziane et al. 2008), whilst exercise-induced activation of AMPK is downregulated (McConell et al. 2005; McConell et al. 2008; Lee-Young et al. 2009; Benziane et al. 2008). Furthermore, after 6 weeks of aerobic training in mice, cardiomyocytes displayed elevated $\mathrm{PLN}^{17}$ phosphorylation in conjunction with increased CaMKII phosphorylation at $\mathrm{Thr}^{287}$ (Kemi et al. 2007). Rose et al. (2007) also previously reported that short-term endurance training elevated CaMKII activity, as well as CaMKII kinase phosphorylation at $\mathrm{Thr}^{287}$. Still, in one other study endurance training was found to attenuate AMPK, but not CaMKII and p38 MAPK signalling, during exercise (Benziane et al. 2008). Whether the changes of eEF2 during exercise and recovery play a role in the adaptive response to endurance training is at present unknown. However, similar protein expression as well as phosphorylation status of eEF2 was found in resting muscle of endurance trained and untrained subjects (Roepstorff et al. 2005).

The dietary context of exercise is also believed to play a crucial role in the exercise-induced activation of AMPK as well as $\mathrm{Ca}^{2+}$-dependent signalling. In this regard, studies by our (De Bock et al. 2005) and other laboratories (Akerstrom et al. 2006) have demonstrated higher AMPK activity in muscles during exercise in the fasted state than during exercise in conjunction with ample exogenous carbohydrate supply, which probably reflects greater challenge of energy balance in the former nutritional condition. Support for such assumption comes from observations showing higher degree of AMP accumulation in muscle for a given exercise intensity when carbohydrate availability is abundant than when it is limited (Spencer et al. 1991; McConell et al. 1999). It is also well established that failing energy homeostasis in muscle cells impairs sarcoplasmatic reticulum $\mathrm{Ca}^{2+}$ reuptake, resulting in elevated cytoplasmic $\mathrm{Ca}^{2+}$ concentration (Allen et al. 2008). If such mechanism also occurs during exercise in the fasted state, this is likely to enhance myocellular adaptations modulated via $\mathrm{Ca}^{2+}$ dependent signalling pathways.

Against this background, the aim of the current study was to compare the effects of endurance training in the fasted state versus training with ample carbohydrate ingestion before and during exercise, on AMPK and $\mathrm{Ca}^{2+}$. dependent signalling during exercise and subsequent recovery. Partial results of this study have been previously published elsewhere (De Bock et al. 2008).

\section{Methods}

Subjects

A total of 20 healthy, physically active men (age: $21.2 \pm 0.4$ years; body wt: $74.8 \pm 2.0 \mathrm{~kg}$ ) volunteered to 
participate in the study, which was approved by the local Ethics Committee (K.U. Leuven). Subjects were instructed not to participate in any strenuous physical activity, except for the exercise sessions prescribed by the study protocol. Subjects gave their written, informed consent after they were informed in detail of all experimental procedures and risks possibly associated with the experiments.

\section{Experimental protocol}

The study protocol has been previously described in detail elsewhere (De Bock et al. 2008). Briefly, 2 weeks before the start of the study the subjects participated in a series of cycle exercise tests to determine $\mathrm{VO}_{2 \text { peak }}$. Subjects were then randomly assigned to one of two groups and participated in two experimental sessions (pretest and posttest), with a 6-week training period in between. On the morning of the pretest, they received a standardized carbohydrate-rich breakfast $(722 \mathrm{kcal}: 85 \%$ of total energy intake [En] carbohydrates, $4 \%$ En from fat, and $11 \%$ En from protein). After a 2-h rest period, a percutaneous needle biopsy sample was taken from the right vastus lateralis muscle. Thereafter subjects cycled for $2 \mathrm{~h}$ at $\sim 75 \% \quad \mathrm{VO}_{2 \text { peak }}$ and received $1 \mathrm{~g}$ maltodextrin $/ \mathrm{kg}$ body $\mathrm{wt} \mathrm{h}^{-1}$ in a $15 \%$ solution. At the end of the exercise bout, another muscle biopsy was taken. During the following 4-h recovery period, the subjects rested in the laboratory and received $1.5 \mathrm{~g}$ maltodextrin/ $\mathrm{kg}$ body wt (15\% flavoured solution) during the initial and the last hour of recovery. Furthermore, between 2 and $3 \mathrm{~h}$ of recovery, they received a solid meal containing $1.5 \mathrm{~g}$ carbohydrates $/ \mathrm{kg}$ body wt. At the end of the recovery period another muscle biopsy was taken. After the pretest the subjects were enrolled in a 6-week supervised training programme (3×/week, 60-120 min) combined with a dietary control regimen (65\% En carbohydrates, 20\% En fat, and $15 \%$ En proteins). One-half of the subjects trained in the fasted state ( $\mathrm{F} ; n=10)$, whereas the others (CHO; $n=10)$ received a carbohydrate-rich breakfast and ingested a $15 \%$ maltodextrin solution during exercise. Subjects from $\mathrm{F}$ and $\mathrm{CHO}$ consistently trained as matched pairs at the same workload. At the end of the 6-week intervention period, subjects participated in the posttest which was identical to the pretest.

Analysis of muscle samples

After being freed from any visible non-muscle material, muscle samples were immediately frozen in liquid nitrogen. All samples were stored at $-80^{\circ} \mathrm{C}$ for later analysis. Muscle specimens were freeze dried and dissected free of visible blood, connective, and fat tissues.
Muscle glycogen

Muscle glycogen content was measured as glucose residues after acid hydrolysis, in freeze-dried muscle tissue using a standard enzymatic fluorometric assay (Lowry and Passoneau 1972).

Muscle lysate production and Western blotting

Samples were homogenized in ice-cold buffer $(20 \mathrm{mM}$ Tris base, $50 \mathrm{mM} \mathrm{NaCl}, 2 \mathrm{mM}$ DTT, $50 \mathrm{mM} \mathrm{NaF}, 1 \%$ Triton $\mathrm{X}-100, \quad 250 \mathrm{mM}$ sucrose, $5 \mathrm{mM}$ Na-pyrophosphate, $4 \mu \mathrm{g} \mathrm{ml}^{-1}$ leupeptin, $6 \mathrm{mM}$ benzamidine, $500 \mu \mathrm{M}$ PMSF, $50 \mu \mathrm{g} / \mathrm{ml}$ soybean trypsin inhibitor, $\mathrm{pH}$ 7.4) for $20 \mathrm{~s}$ using a homogenizer (Polytron 2000, Kinematica, Littau, Switzerland). Homogenates were rotated end over end for $1 \mathrm{~h}$ at $4^{\circ} \mathrm{C}$. Lysates were generated by centrifugation $(17,500 \mathrm{~g})$ for $1 \mathrm{~h}$ at $4^{\circ} \mathrm{C}$. Lysates were quick frozen in liquid nitrogen and stored at $-80^{\circ} \mathrm{C}$. Protein content in lysates was measured by the bicinchoninic acid method (Pierce Chemical Company, Ill., USA). Equal amounts of muscle extract protein were separated by SDS-PAGE, transferred to a polyvinylidene fluoride membrane, after which membrane was blocked at room temperature for $1 \mathrm{~h}$ in TBS-T (Tris-buffered saline containing $0.05 \%$ Tween 20, pH 7.4) comprising 2 or 5\% skimmed milk powder. Blocked membranes were incubated with primary and secondary antibodies for optimized times and concentrations, and washed with TBS-T. Proteins were visualized by chemiluminescence (ECL plus, Amersham Biosciences, UK). The primary antibodies used were anti-phospho$\mathrm{Thr}^{56}$-eEF2 (Cell Signalling Technology Inc., USA; 2331), anti-phospho-Thr ${ }^{172}$-AMPK $\alpha$ (Cell Signalling Technology Inc., USA; 2531), anti-phospho-Ser ${ }^{221}$-ACC $\beta$ (Cell Signalling Technology Inc., USA, 3661), anti-phospho-p38 MAPK (Cell Signalling Technology Inc., USA, 9211), and anti-phospho-Thr ${ }^{17}$-PLN (Cyclacel, UK, 010-13). Secondary antibodies were from DakoCytomation. Band density was calculated by using Kodak 1D image analysis software.

\section{Statistical analyses}

Treatment effects were evaluated using a repeated-measures ANOVA. Two-way ANOVA was performed to examine the main effects of treatment and/or time. In case the ANOVA yielded a significant effect, a planned contrast analysis was used for post hoc comparisons. In addition, contrast analysis was also used to evaluate specific preplanned comparisons. A probability level $(P)<0.05$ was considered statistically significant. All data are expressed as mean $\pm \mathrm{SE}$. 


\section{Results}

eEF2 (Fig. 1)

Compared with the pretest, baseline eEF2 phosphorylation status was markedly increased in $\mathrm{CHO}(+50 \%, P<0.05)$, but not in $\mathrm{F}(+7 \%, P=0.66)$. Still, changes from the pretest to the posttest were not significantly different between the groups $(P=0.22)$. The immediate exercise response was affected by training in neither group. However, in the posttest, eEF2 phosphorylation status returned to baseline within $4 \mathrm{~h}$ of recovery in $\mathrm{F}$, whilst it remained elevated in $\mathrm{CHO}(P<0.05)$. However, the change in the degree of eEF2 phosphorylation status during recovery was not significantly different between the groups $(P=0.22)$.

\section{PLN (Fig. 2)}

To evaluate the effect of training on $\mathrm{Ca}^{2+}{ }_{-} \mathrm{CaM}-\mathrm{CaMKII}$ signalling, we measured PLN phosphorylation at $\mathrm{Thr}^{17}$, which is proposed to be indicative for in vivo CaMKII activity (Rose et al. 2006). In the pretest, baseline PLN ${ }^{17}$ phosphorylation status was similar between $\mathrm{F}$ and $\mathrm{CHO}$. Compared with the pretest, baseline $\mathrm{PLN}^{17}$ phosphorylation status in the posttest was slightly increased both in $\mathrm{CHO}(+18 \%, P<0.05)$ and in $\mathrm{F}(+15 \%, P=0.07)$. Changes in the degree of $\mathrm{PLN}^{17}$ phosphorylation during exercise and recovery were similar between the groups in the pretest as well as in the posttest.

\section{$\mathrm{AMPK} \alpha$ and $\mathrm{ACC} \beta$ (Fig. 3)}

The training intervention significantly increased $(\sim+35 \%)$ basal AMPK $\alpha$ phosphorylation status, whereas the exercise-

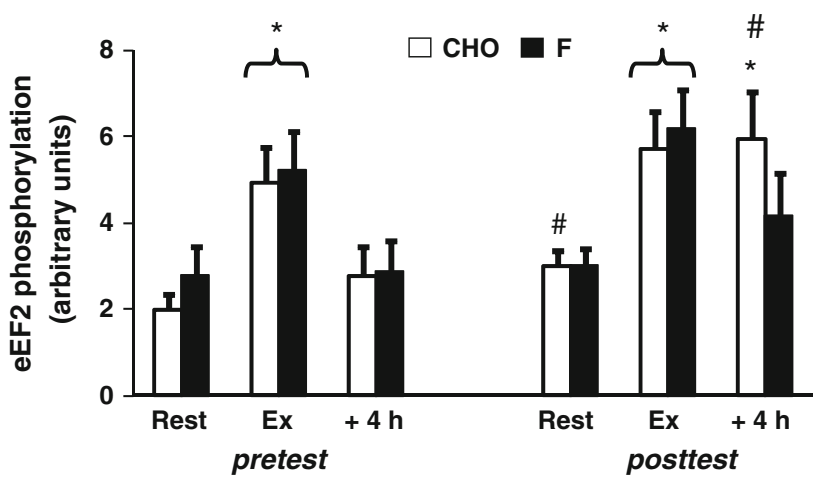

Fig. 1 Effect of 6 weeks training in the fasted state versus the high carbohydrate state on phosphorylation of muscle eEF2 during an acute exercise bout. $\mathrm{Thr}^{56}$ phosphorylation on eEF2 was measured by Western blotting on muscle samples obtained before (Rest), immediately after $(\mathrm{Ex})$, and $4 \mathrm{~h}$ after $(+4 \mathrm{~h})$ a 2 -h constant-load exercise bout. Data are given as mean arbitrary scanning units \pm S.E.M. $* P<0.05$ indicates a difference compared with Rest. ${ }^{\#} P<0.05$ indicates a difference compared with the corresponding value in the pretest

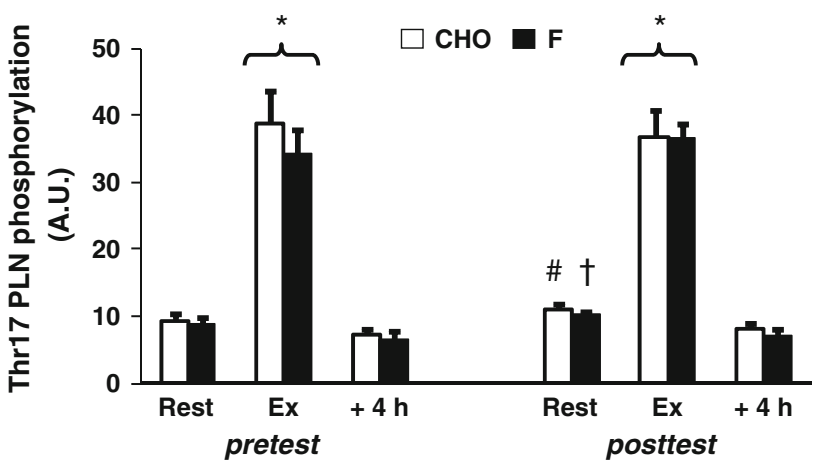

Fig. 2 Effect of 6 weeks training in the fasted state versus the high carbohydrate state on phosphorylation of muscle $\mathrm{PLN}^{17}$ during an acute exercise bout. PLN phosphorylation at $\mathrm{Thr}^{17}$ was measured by Western blotting on muscle samples obtained before (Rest), immediately after $(E x)$, and $4 \mathrm{~h}$ after $(+4 \mathrm{~h})$ a 2 -h constant-load exercise bout. Data are given as mean arbitrary scanning units \pm S.E.M. ${ }^{*} P<0.05$ indicates a difference compared with Rest. ${ }^{\#} P<0.05$ indicates a difference compared with the corresponding value in the pretest. ${ }^{\dagger} P=0.07$ versus the corresponding value in the pretest

induced increase in phosphorylation was blunted in both groups $(P<0.001)$. In fact, during the posttest the degree of AMPK $\alpha$ phosphorylation was slightly decreased following exercise in CHO $(P<0.05)$, but not in F. Still, the training-induced change in AMPK $\alpha$ phosphorylation status after exercise was not significantly different between the groups $(P=0.30)$. In parallel with the changes in AMPK $\alpha$, pre-exercise ACC $\beta$ phosphorylation was higher in the posttest than in the pretest, whilst the rise in $\mathrm{ACC} \beta$ phosphorylation immediately after exercise was negated by training in $\mathrm{F}$ as well as in $\mathrm{CHO}(P<0.05)$. Nonetheless, in the pretest the exercise still slightly increased the degree of ACC $\beta$ phosphorylation in $\mathrm{F}(P<0.01)$, but not in $\mathrm{CHO}$ $(P=0.18)$. However, again the changes from the pretest to the posttest were not significantly different between the groups $(P=0.14)$.

p38 MAPK (Fig. 4)

As p38 MAPK lies downstream of CAMKII and mediates a variety of metabolic processes, we also measured the phosphorylation status of p38 MAPK. Baseline p38 MAPK phosphorylation was similar between the pretest and the posttest in both $\mathrm{F}$ and $\mathrm{CHO}$. In the pretest, but not in the posttest, exercise stimulated p38 MAPK phosphorylation in each group $(P<0.05)$. Values were not significantly different between $\mathrm{F}$ and $\mathrm{CHO}$ at any time.

Muscle glycogen (Table 1)

During the pretest, muscle glycogen content was similar between the groups before and after exercise. Compared with the pretest, during the posttest initial glycogen content 

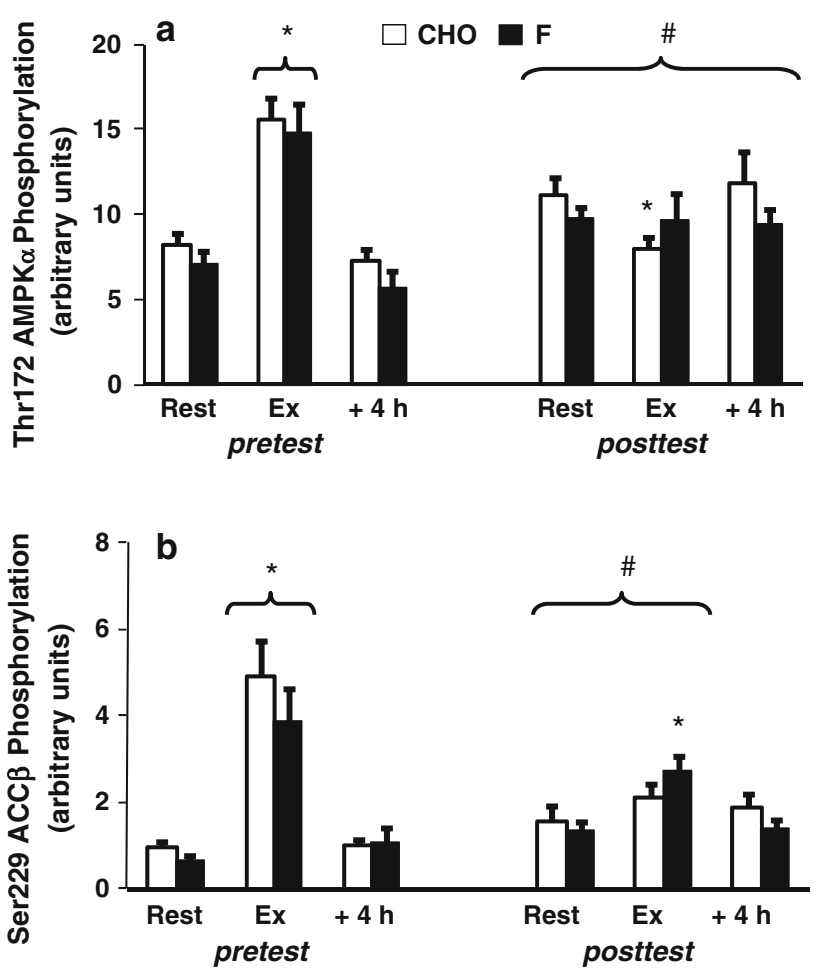

Fig. 3 Effect of 6 weeks training in the fasted state versus the high carbohydrate state on phosphorylation of muscle AMPK $\alpha$ and ACC $\beta$ during an acute exercise bout. $\mathrm{Thr}^{172}$ phosphorylation on AMPK $\alpha$ (a) and $\operatorname{Ser}^{221}$ phosphorylation of $\operatorname{ACC} \beta$ (b) were measured by Western blotting on muscle samples obtained before (Rest), immediately after (Ex), and $4 \mathrm{~h}$ after $(+4 \mathrm{~h})$ a 2 -h constant-load exercise bout. Data are given as mean arbitrary scanning units \pm S.E.M. ${ }^{*} P<0.05$ indicates a difference compared with Rest. ${ }^{\#} P<0.05$ indicates a difference compared with the corresponding value in the pretest

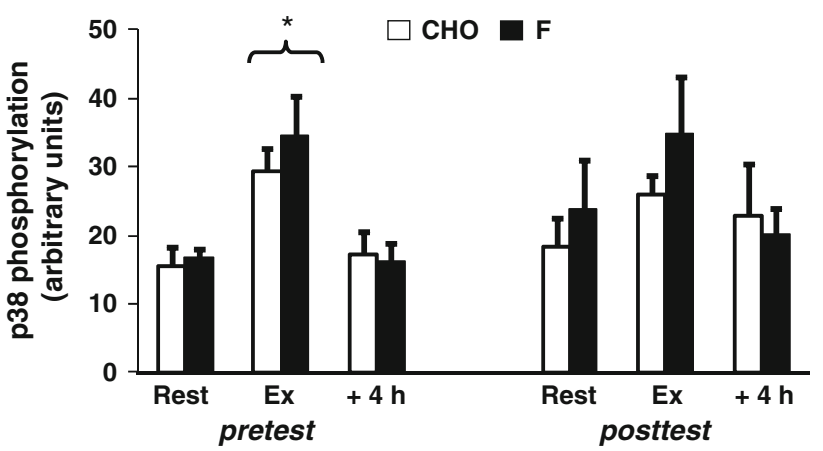

Fig. 4 Effect of 6 weeks training in the fasted state versus the high carbohydrate state on phosphorylation of muscle p38 MAPK during an acute exercise bout. p38 MAPK phosphorylation was measured by Western blotting on muscle samples obtained before (Rest), immediately after (Ex), and $4 \mathrm{~h}$ after $(+4 \mathrm{~h})$ a 2-h constant-load exercise bout. Data are given as mean arbitrary scanning units \pm S.E.M. ${ }^{*} P<0.05$ indicates a difference compared with Rest

was increased in $\mathrm{CHO}(P<0.05)$, but not in $\mathrm{F}(P=0.23)$. The training intervention resulted in higher post-exercise glycogen levels in both groups $(P<0.05)$.
Table 1 Effect of 6 weeks training in the fasted state versus the high carbohydrate state on muscle glycogen content during an acute exercise bout

\begin{tabular}{lll}
\hline & $\mathrm{F}$ & $\mathrm{CHO}$ \\
\hline Pretest & & \\
Rest & $378 \pm 34$ & $425 \pm 49$ \\
Ex & $167 \pm 21^{*}$ & $158 \pm 24^{*}$ \\
$+4 \mathrm{~h}$ & $246 \pm 23^{*}$ & $275 \pm 28^{*}$ \\
Posttest & & \\
Rest & $434 \pm 33$ & $545 \pm 20^{\#}$ \\
Ex & $295 \pm 25^{*}, \#$ & $241 \pm 17^{*}, \#$ \\
$+4 \mathrm{~h}$ & $348 \pm 26^{*}, \#$ & $340 \pm 26^{*}, \#$ \\
\hline
\end{tabular}

Muscle glycogen content was measured using a standard enzymatic fluorometric assay before (Rest), immediately after (Ex), and $4 \mathrm{~h}$ after $(+4 \mathrm{~h})$ a 2 -h constant-load exercise bout. Data are given as mean mmol kg ${ }^{-1}$ dry weight \pm S.E.M.

$* P<0.05$ indicates a difference compared with Rest

${ }^{\#} P<0.05$ indicates a difference compared with the corresponding value in the pretest

\section{Discussion}

Long-term training adaptations result from the sequential impact of acute responses to repeated exercise bouts. It is also well established that the metabolic responses of muscle cells to a given exercise mode depend on the nutritional status (De Bock et al. 2005; De Bock et al. 2007a; Deldique et al. 2010; Wagenmakers et al. 1991; Cluberton et al. 2005; Civitarese et al. 2005). Thus, longterm adaptations to training conceivably also depend on the nutrient intake before, during, and after the exercise sessions. It is well documented that exercise in the fasted state, compared with exercise in the fed state, generates a number of specific metabolic responses, most typically enhanced contribution of fat oxidation in energy provision, but also higher rate of muscle protein degradation (Gibala 2007; Koopman et al. 2004). Furthermore, net muscle protein breakdown is markedly enhanced during exercise when muscle glycogen stores are depleted (Wagenmakers et al. 1991; Jackman et al. 1997). In this regard, we have previously shown that net glycogen degradation is enhanced during exercise in the fasted state (De Bock et al. 2007a), which conceivably could result in premature glycogen depletion. Moreover, carbohydrate availability during the later stage of exercise in the fasted state is also limited due to liver glycogen depletion and thereby drop of blood glucose availability (Coggan and Coyle 1991). We recently have also demonstrated that $\mathrm{p} 70^{\mathrm{s} 6 \mathrm{k}}$ phosphorylation is enhanced following a resistance exercise bout in the fasted state, which indicates increased muscle anabolism (Deldique et al. 2010). Against this background and in line with the opinion that long-term training adaptations result 
from the sequential action of acute exercise responses, we anticipated that consistent exercise training in the fasted state could trigger myocellular adaptations to facilitate post-exercise protein repair to compensate for the enhanced degradation during exercise. Consistent with such assumption, endurance training in the fasted state, compared with an identical training programme in the high carbohydrate state, facilitated post-exercise dephosphorylation (see Fig. 1) and thus activation of eEF2. This in turn probably contributes to rapid stimulation of net protein synthesis by virtue of facilitated protein translation in muscle cells during early recovery (Dreyer et al. 2006).

In keeping with earlier findings (Rose et al. 2005), acute exercise markedly increased eEF2 phosphorylation. Here, we add to this observation that the degree of exerciseinduced eEF2 inactivation ( $\sim$ phosphorylation) was not altered by short-term training in the fasted or high carbohydrate state (see Fig. 1). During recovery, however, activation of eEF2 by dephosphorylation (Dreyer et al. 2006) occurred more rapidly following training in the fasted state, than after training in the fed state with ample carbohydrate supplementation during exercise. It is also important to remind that the exercise test in the pretest as well as in the posttest, in contrast with the exercise sessions during the 6-week training period, was performed with ample carbohydrate supplementation before, during and after exercise. Such protocol was resolutely chosen because endurance athletes as a rule perform regular training in the fasted state aiming to improve performance during endurance competitions associated with ample carbohydrate supply before and during exercise. Therefore, our current findings indicate that acute high-dose carbohydrate intake does not negate the effect of prolonged training in the fasted state to stimulate rapid post-exercise eEF2 dephosphorylation and thereby re-activation of protein translation. Alternatively, we cannot exclude that this effect was at least partly due to an abrupt switch from habitual exercise in the fasted state to exercise with plenty of carbohydrate intake. The study protocol did not include an additional exercise trial with the participants fasted, which could have allowed to isolate the effects of training from the effect of diet on eEF2 activation. However, a number of arguments support the conclusion that the sustained post-exercise activation of eEF2 is likely due to the consistent fasted training. There is evidence to indicate that besides regulation by $\mathrm{Ca}^{2+}$ and AMPK, eEF2 activity can also be downregulated by cAMP-dependent protein kinase, versus upregulated via insulin-stimulated activation of the mammalian target of rapamycin complex 1 (Rose and Richter 2009). First, compared with exercise in the fasted state, during exercise with ample carbohydrate intake the facilitated energy balance (Spencer et al. 1991; McConell et al 1999) in conjunction with higher plasma insulin concentration (De Bock et al. 2005) may suppress exerciseinduced inhibition of eEF2. This in turn may reduce the need for rapid eEF2 re-activation during early recovery. Thus, if no training adaptations were present one would rather expect a blunted eEF2 response after an exercise bout with high carbohydrate availability following a period of consistent fasted exercise. Second, given the greater rate of muscle protein degradation during exercise in the carbohydrate-depleted state than during exercise with high carbohydrate availability (Gibala 2007; Wagenmakers et al. 1991; Jackman et al. 1997; Koopman et al. 2004), rapid re-activation of eEF2 conceivably could contribute to facilitating post exercise protein repair during a period of consistently repeated exercise in the fasted state. Such mechanism is probably redundant during consistent exercise training with ample carbohydrate intake.

There are some literature data to suggest that the greater energy challenge during muscle contractions with limited carbohydrate availability, like exercise in the fasted state, also could facilitate activation of downstream targets of $\mathrm{Ca}^{2+}$ in muscle cells other than eEF2, such as AMPK $\alpha$ (De Bock et al. 2005; Akerstrom et al. 2006) and $\mathrm{PLN}^{17}$ (Rose et al. 2006). However, contrary to such assumption, independent of the dietary condition 6 weeks of training elicited similar adaptations of $\mathrm{AMPK} \alpha, \operatorname{ACC} \beta$ as well as $\mathrm{PLN}^{17}$ activation. Before training $(\sim$ pretest $)$ the $2 \mathrm{~h}$ constant-load exercise bout $(171 \pm 4 \mathrm{~W})$ markedly activated AMPK, as evidenced by increased AMPK $\alpha$ phosphorylation status. The 6 -week training programme expectedly negated this exercise-induced activation of AMPK (McConell et al. 2005, 2008; Benziane et al. 2008) (see Fig. 3a), which probably reflects facilitated energy homeostasis in muscle cells during a given absolute exercise intensity after a training period (Chesley et al. 1996; McConell et al. 2005). The effect of training to undo the exercise-induced activation of AMPK was independent of whether the training was performed in the fasted or high carbohydrate state. By analogy, the exercise-induced activation of ACC $\beta$, an important downstream target of AMPK (Winder et al. 1997), was similarly reduced by training in both groups (see Fig. 3b). It has also been shown by some, but not by others (Rose et al. 2005; Rose et al. 2009; Miranda et al. 2008) that AMPK can phosphorylate eEF2, and thereby probably inhibit the process of protein elongation (Hong-Brown et al. 2007; Horman et al. 2002). However, in support of the latter opinion, we here clearly demonstrate that inhibition of the exercise-induced activation of AMPK by short-term endurance training (Fig. 3a), independent of the dietary condition, was not associated with downregulation of exercise-induced phosphorylation of eEF2 (Fig. 1). This again indicates that AMPK is probably not directly implicated in modulating training-induced adaptations of muscle protein translation 
by regulation of eEF2 phosphorylation status. It has been shown that increased muscle glycogen content blunts exercise-induced activation of AMPK (Derave et al. 2000; Wojtaszewski et al. 2003). Basal muscle glycogen content was elevated following consistent exercise with high carbohydrate intake, but not after training in the fasted state. Still, 6 weeks of endurance training similarly decreased AMPK phosphorylation during exercise in both groups (Fig. 3a). This indicates a dissociation between initial glycogen level and exercise-induced AMPK activation after an episode of endurance exercise training, which corroborates some earlier observations (McConell et al. 2005; Yeo et al. 2008a; Van Proeyen et al., unpublished observations).

Phosphorylation of phospholamban at $\mathrm{Th}^{17}\left(\mathrm{PLN}^{17}\right)$ reflects in vivo calmodulin kinase II (CaMKII) activity, which lies upstream of AMPK and is believed to play a pivotal role in $\mathrm{Ca}^{2+}$-mediated intracellular signalling in muscle cells (Rose et al. 2006). Our current data demonstrate that in resting muscle the degree of $\mathrm{PLN}^{17}$ phosphorylation was increased by $\sim 15 \%$ following training in both experimental groups (Fig. 2). By analogy, Kemi et al. (2007) found higher PLN ${ }^{17}$ phosphorylation in mouse cardiac muscle after 6 weeks of training, which supports the conclusion that endurance training upregulates basal CaMKII activity in muscle cells. Still, training must probably be maintained for a sufficiently long period because training interventions of less than 3 weeks have been found ineffective to elevate baseline PLN ${ }^{17}$ phosphorylation in muscles (Benziane et al. 2008; Rose et al. 2007). Against the face of increased baseline $\mathrm{PLN}^{17}$ phosphorylation status, the current training intervention affected neither the exercise-induced rise in PLN $^{17}$ activation nor the subsequent decline during recovery, which is compatible with the observations in one earlier short-term training study in humans (Benziane et al. 2008) and indicates that short-term training does not alter contractioninduced stimulation of CaMKII in muscle.

There is some evidence to indicate that p38 MAPK is probably implicated in $\mathrm{Ca}^{2+}$-induced stimulation of mitochondrial biogenesis in muscle cells (Wright et al. 2007). Consistent with earlier findings, we found acute exercise to increase p38 MAPK, but this effect was not altered by training in either the fasted state or in the high carbohydrate state (Fig. 4), which is in line with one earlier study (Benziane et al. 2008). However, cross-sectional studies have found either unchanged (Nielsen et al. 2003) or decreased (Yu et al. 2003; Coffey et al. 2006) p38 MAPK signalling in endurance-trained subjects compared with sedentary controls. Furthermore, Coffey et al. (2006) found that p38 MAPK activation was blunted when trained subjects undertook their habitual exercise, but not when they participated in another activity mode. In this regard, switching from exercise in the fasted state to exercise with ample carbohydrate ingestion, and thereby increasing the contribution of carbohydrate oxidation in ATP production, was not a stimulus to significantly alter p38 MAPK signalling. In addition, other stress stimuli like for instance inflammatory cytokines (Raingeaud 1995), cell membrane stretching (Chambers 2009), or mitochondrial production of reactive oxygen species (Emerling 2005), which also can trigger p38 MAPK activation, probably were not affected by the nutritional status during training.

Finally, the current findings result from biochemical assays in mixed muscle extracts from m. vastus lateralis, which in healthy young men on average is composed of about $55 \%$ type I, versus $\sim 45 \%$ type II fibres (Lucia et al. 2002; De Bock et al. 2007b). Nonetheless, prolonged endurance exercise primarily involves recruitment of type I motor units, leaving a large fraction of the type II motor units inactive (Hultman 1995; Vollestad and Blom 1985). Therefore, such approach conceivably underestimates the true amplitude of contraction-induced regulation of intramyocellular signalling pathways.

In conclusion, the current study provides novel evidence to indicate that consistent endurance exercise training in the fasted state may contribute to facilitate rapid postexercise re-activation of muscle protein translation by dephosphorylation of eEF2. This finding once more indicates that the nutritional status, i.e. exercise in the fasted state versus exercise in the carbohydrate repleted state, is an important factor to modulating muscular adaptations resulting from a given exercise training programme.

Acknowledgments The authors thank Erik A. Richter and Adam J. Rose, Copenhagen Muscle Research Centre, Institute of Exercise and Sports Sciences, University of Copenhagen, Copenhagen, Denmark Research Centre, for researching data. Monique Ramaekers, Research Centre for Exercise and Health, Department of Biomedical Kinesiology, K.U. Leuven, is also greatly acknowledged for all efforts she has put in this study. This study was supported by grant OT/05/53 from the Katholieke Universiteit Leuven and grant G.0233.05 F from the Fund for Scientific Research-Flanders, Belgium (F.W.O.Vlaanderen).

Conflict of interest There is no conflict of interest.

\section{References}

Akerstrom TCA, Birk JB, Klein DK, Erikstrup C, Plomgaard P, Pedersen BK, Wojtaszewski JF (2006) Oral glucose ingestion attenuates exercise-induced activation of $5^{\prime}$-AMP-activated protein kinase in human skeletal muscle. Biochem Biophys Res Commun 342:949-955

Akimoto T, Pohnert SC, Li P, Zhang M, Gumbs C, Rosenberg PB, Williams RS, Yan Z (2005) Exercise stimulates Pgc-1a transcription in skeletal muscle through activation of the p38 MAPK pathway. J Biol Chem 280:19587-19593 
Allen DG, Lamb GD, Westerblad H (2008) Skeletal muscle fatigue: cellular mechanisms. Physiol Rev 88:287-332

Benziane B, Burton TJ, Scanlan B, Galuska D, Canny BJ, Chibalin AV, Zierath JR, Stepto NK (2008) Divergent cell signaling after short-term intensified endurance training in human skeletal muscle. Am J Physiol Endocrinol Metab 295:E1427-E1438

Chambers MA, Moylan JS, Smith JD, Goodyear LJ, Reid MB (2009) Stretch-stimulated glucose uptake in skeletal muscle is mediated by reactive oxygen species and p38 MAP-kinase. J Physiol 587:3363-3373

Chesley A, Heigenhauser GJ, Spriet LL (1996) Regulation of muscle glycogen phosphorylase activity following short-term endurance training. Am J Physiol Endocrinol Metab 270:E328-E335

Chin ER (2005) Role of Ca2+/calmodulin-dependent kinases in skeletal muscle plasticity. J Appl Physiol 99:414-423

Civitarese AE, Hesselink MKC, Russell AP, Ravussin E, Schrauwen $P$ (2005) Glucose ingestion during exercise blunts exerciseinduced gene expression of skeletal muscle fat oxidative genes. Am J Physiol Endocrinol Metab 289:E1023-E1029

Cluberton LJ, McGee SL, Murphy RM, Hargreaves M (2005) Effect of carbohydrate ingestion on exercise-induced alterations in metabolic gene expression. J Appl Physiol 99:1359-1363

Coffey VG, Zhong Z, Shield A, Canny BJ, Chibalin AV, Zierath JR, Hawley JA (2006) Early signaling responses to divergent exercise stimuli in skeletal muscle from well-trained humans. FASEB J 20:190-192

Coggan AR, Coyle EF (1991) Carbohydrate ingestion during prolonged exercise: effects on metabolism and performance. Exerc Sport Sci Rev 19:1-40

De Bock K, Richter EA, Russell AP, Eijnde BO, Derave W, Ramaekers M, Koninckx E, Leger B, Verhaeghe J, Hespel P (2005) Exercise in the fasted state facilitates fibre type-specific intramyocellular lipid breakdown and stimulates glycogen resynthesis in humans. J Physiol 564:649-660

De Bock K, Derave W, Ramaekers M, Richter EA, Hespel P (2007a) Fiber type-specific muscle glycogen sparing due to carbohydrate intake before and during exercise. J Appl Physiol 102:183-188

De Bock K, Dresselaers T, Kiens B, Richter EA, Van Hecke P, Hespel P (2007b) Evaluation of intramyocellular lipid breakdown during exercise by biochemical assay, NMR spectroscopy, and Oil Red $\mathrm{O}$ staining. Am J Physiol Endocrinol Metab 293:E428-E434

De Bock K, Derave W, Eijnde BO, Hesselink MKC, Koninckx E, Rose AJ, Schrauwen P, Bonen A, Richter EA, Hespel PJ (2008) Effect of training in the fasted state on metabolic responses during exercise with carbohydrate intake. J Appl Physiol 104:1045-1055

Deldique L, De Bock K, Maris M, Ramaekers M, Nielens H, Francaux M, Hespel P (2010) Increased p70 ${ }^{\mathrm{s} 6 \mathrm{k}}$ phosphorylation during intake of a protein-carbohydrate drink following resistance exercise in the fasted state. Eur J Appl Physiol 108:791-800

Derave W, Ai H, Ihlemann J, Witters LA, Kristiansen S, Richter EA, Ploug T (2000) Dissociation of AMP-activated protein kinase activation and glucose transport in contracting slow-twitch muscle. Diabetes 49:1281-1287

Dreyer HC, Fujita S, Cadenas JG, Chinkes DL, Volpi E, Rasmussen BB (2006) Resistance exercise increases AMPK activity and reduces 4E-BP1 phosphorylation and protein synthesis in human skeletal muscle. J Physiol 576:613-624

Emerling BM, Platanias LC, Black E, Nebreda AR, Davis RJ, Chandel NS (2005) Mitochondrial reactive oxygen species activation of $\mathrm{p} 38$ mitogen-activated protein kinase is required for hypoxia signaling. Mol Cell Biol 25:4853-4862

Frosig C, Jorgensen SB, Hardie DG, Richter EA, Wojtaszewski JFP (2004) 5'-AMP-activated protein kinase activity and protein expression are regulated by endurance training in human skeletal muscle. Am J Physiol Endocrinol Metab 286:E411-E417

Gibala MJ (2007) Protein metabolism and endurance exercise. Sports Med 37:337-340

Hansen AK, Fischer CP, Plomgaard P, Andersen JL, Saltin B, Pedersen BK (2005) Skeletal muscle adaptation: training twice every second day vs. training once daily. J Appl Physiol 98:93-99

Hawley SA, Pan DA, Mustard KJ, Ross L, Bain J, Edelman AM, Frenguelli BG, Hardie DG (2005) Calmodulin-dependent protein kinase kinase-[beta] is an alternative upstream kinase for AMPactivated protein kinase. Cell Metab 2:9-19

Hong-Brown LQ, Brown CR, Huber DS, Lang CH (2007) Alcohol regulates eukaryotic elongation factor 2 phosphorylation via an AMP-activated protein kinase-dependent mechanism in $\mathrm{C} 2 \mathrm{C} 12$ skeletal myocytes. J Biol Chem 282:3702-3712

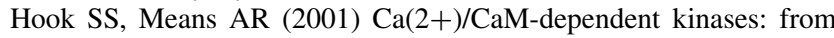
activation to function. Annu Rev Pharmacol Toxicol 41:471-505

Horman S, Browne GJ, Krause U, Patel JV, Vertommen D, Bertrand L, Lavoinne A, Hue L, Proud CG, Rider MH (2002) Activation of AMP-activated protein kinase leads to the phosphorylation of elongation factor 2 and an inhibition of protein synthesis. Curr Biol 12:1419-1423

Hulston CJ, Venables MC, Mann CH, Martin C, Philp A, Baar K, Jeukendrup AE (2010) Training with low muscle glycogen enhances fat metabolism in well-trained cyclists. Med Sci Sports Exerc 42:2046-2055

Hultman E (1995) Fuel selection, muscle fibre. Proc Nutr Soc 54:107-121

Hurley RL, Anderson KA, Franzone JM, Kemp BE, Means AR, Witters LA (2005) The $\mathrm{Ca} 2+/$ calmodulin-dependent protein kinase kinases are AMP-activated protein kinase kinases. J Biol Chem 280:29060-29066

Jackman ML, Gibala MJ, Hultman E, Graham TE (1997) Nutritional status affects branched-chain oxoacid dehydrogenase activity during exercise in humans. Am J Physiol Endocrinol Metab 272:E233-E238

Jensen TE, Rose AJ, Jorgensen SB, Brandt N, Schjerling P, Wojtaszewski JFP, Richter EA (2007) Possible CaMKK-dependent regulation of AMPK phosphorylation and glucose uptake at the onset of mild tetanic skeletal muscle contraction. Am J Physiol Endocrinol Metab 292:E1308-E1317

Jorgensen SB, Richter EA, Wojtaszewski FP Jr (2006) Role of AMPK in skeletal muscle metabolic regulation and adaptation in relation to exercise. J Physiol 574:17-31

Kemi OJ, Ellingsen Ï, Ceci M, Grimaldi S, Smith GL, Condorelli G, Wisl ff U (2007) Aerobic interval training enhances cardiomyocyte contractility and $\mathrm{Ca} 2+$ cycling by phosphorylation of CaMKII and Thr-17 of phospholamban. J Mol Cell Cardiol 43:354-361

Koopman R, Pannemans DLE, Jeukendrup AE, Gijsen AP, Senden JMG, Halliday D, Saris WHM, van Loon LJC, Wagenmakers AJM (2004) Combined ingestion of protein and carbohydrate improves protein balance during ultra-endurance exercise. Am J Physiol Endocrinol Metab 287:E712-E720

Lee-Young RS, Canny BJ, Myers DE, McConell GK (2009) AMPK activation is fiber type specific in human skeletal muscle: effects of exercise and short-term exercise training. J Appl Physiol 107:283-289

Lowry OH, Passoneau JV (1972) A flexible system of enzymatic analysis. Academic Press, New York

Lucia A, Rivero JL, Perez M, Serrano AL, Calbet JA, Santalla A, Chicarro JL (2002) Determinants of $\mathrm{O}_{2}$ kinetics at high power outputs during a ramp exercise protocol. Med Sci Sports Exerc $34: 331$ 
McConell G, Snow RJ, Proietto J, Hargreaves M (1999) Muscle metabolism during prolonged exercise in humans: influence of carbohydrate availability. J Appl Physiol 87:1083-1086

McConell GK, Lee-Young RS, Chen ZP, Stepto NK, Huynh NN, Stephens TJ, Canny BJ, Kemp BE (2005) Short-term exercise training in humans reduces AMPK signalling during prolonged exercise independent of muscle glycogen. J Physiol 568:665-676

McConell GK, Manimmanakorn A, Lee-Young RS, Kemp BE, Linden KC, Wadley GD (2008) Differential attenuation of AMPK activation during acute exercise following exercise training or AICAR treatment. J Appl Physiol 105:1422-1427

Miranda L, Horman S, De Potter I, Hue L, Jensen J, Rider M (2008) Effects of contraction and insulin on protein synthesis, AMPactivated protein kinase and phosphorylation state of translation factors in rat skeletal muscle. Pflugers Archiv 455:1129-1140

Nielsen JN, Frosig C, Sajan MP, Miura A, Standaert ML, Graham DA, JrFP Wojtaszewski, Farese RV, Richter EA (2003) Increased atypical PKC activity in endurance-trained human skeletal muscle. Biochem Biophys Res Commun 312:1147-1153

Nybo L, Pedersen K, Christensen B, Aagaared P, Brandt N, Kiens B (2009) Impact of carbohydrate supplementation during endurance training on glycogen storage and performance. Acta Physiologica 197:117-127

Raingeaud J, Gupta S, Rogers JS, Dickens M, Han J, Ulevitch RJ, Davis RJ (1995) Proinflammatory cytokines and environmental stress cause p38 mitogen-activated protein kinase activation by dual phosphorylation on tyrosine and threonine. J Biol Chem 270:7420-7426

Roepstorff C, Schjerling P, Vistisen B, Madsen M, Steffensen CH, Rider MH, Kiens B (2005) Regulation of oxidative enzyme activity and eukaryotic elongation factor 2 in human skeletal muscle: influence of gender and exercise. Acta Physiol Scand 184:215-224

Rose AJ, Richter EA (2009) Regulatory mechanisms of skeletal muscle protein turnover during exercise. J Appl Physiol 106:1702-1711

Rose AJ, Broholm C, Kiillerich K, Finn SG, Proud CG, Rider MH, Richter EA, Kiens B (2005) Exercise rapidly increases eukaryotic elongation factor 2 phosphorylation in skeletal muscle of men. J Physiol 569:223-228

Rose AJ, Kiens B, Richter EA (2006) Ca2+/calmodulin-dependent protein kinase expression and signalling in skeletal muscle during exercise. J Physiol 574:889-903

Rose AJ, Frosig C, Kiens B, JrFP Wojtaszewski, Richter EA (2007) Effect of endurance exercise training on $\mathrm{Ca} 2+/$ calmodulindependent protein kinase II expression and signalling in skeletal muscle of humans. J Physiol 583:785-795

Rose AJ, Alsted TJ, Jensen TE, Kobberø JB, Maarbjerg SJ, Jensen $\mathrm{J}+$, Richter EA (2009) A Ca(2+)-calmodulin-eEF2K-eEF2 signalling cascade, but not AMPK, contributes to the suppression of skeletal muscle protein synthesis during contractions. J Physiol 587:1547-1563

Spencer MK, Yan Z, Katz A (1991) Carbohydrate supplementation attenuates IMP accumulation in human muscle during prolonged exercise. Am J Physiol Cell Physiol 261:C71-C76

Van Proeyen K, Szlufcik K, Nielens H, Pelgrim K, Deldicque L, Hesselink M, Van Veldhoven PP, Hespel P (2010) Training in the fasted state improves glucose tolerance during fat-rich diet. J Physiol 588:4289-4302

Vollestad NK, Blom PC (1985) Effect of varying exercise intensity on glycogen depletion in human muscle fibres. Acta Physiol Scand 125:395-405

Wagenmakers AJ, Beckers EJ, Brouns F, Kuipers H, Soeters PB, Van Der Vusse GJ, Saris WH (1991) Carbohydrate supplementation, glycogen depletion, and amino acid metabolism during exercise. Am J Physiol Endocrinol Metab 260:E883-E890

Winder WW, Wilson HA, Hardie DG, Rasmussen BB, Hutber CA, Call GB, Clayton RD, Conley LM, Yoon S, Zhou B (1997) Phosphorylation of rat muscle acetyl-CoA carboxylase by AMPactivated protein kinase and protein kinase A. J Appl Physiol $82: 219-225$

Wojtaszewski JFP, MacDonald C, Nielsen JN, Hellsten Y, Hardie DG, Kemp BE, Kiens B, Richter EA (2003) Regulation of 5'AMP-activated protein kinase activity and substrate utilization in exercising human skeletal muscle. Am J Physiol Endocrinol Metab 284:E813-E822

Wright DC (2007) Mechanisms of calcium-induced mitochondrial biogenesis and GLUT4 synthesis. Appl Physiol Nutr Metab 32:840-845

Wright DC, Geiger PC, Han DH, Jones TE, Holloszy JO (2007) Calcium induces increases in peroxisome proliferator-activated receptor coactivator- $1 \mathrm{a}$ and mitochondrial biogenesis by a pathway leading to $\mathrm{p} 38$ mitogen-activated protein kinase activation. J Biol Chem 282:18793-18799

Yeo WK, Lessard SJ, Chen ZP, Garnham AP, Burke LM, Rivas DA, Kemp BE, Hawley JA (2008a) Fat adaptation followed by carbohydrate restoration increases AMPK activity in skeletal muscle from trained humans. J Appl Physiol 105:1519-1526

Yeo WK, Paton CD, Garnham AP, Burke LM, Carey AL, Hawley JA (2008b) Skeletal muscle adaptation and performance responses to once a day versus twice every second day endurance training regimens. J Appl Physiol 105:1462-1470

Yu M, Stepto NK, Chibalin AV, Fryer LGD, Carling D, Krook A, Hawley JA, Zierath JR (2003) Metabolic and mitogenic signal transduction in human skeletal muscle after intense cycling exercise. J Physiol 546:327-335 